\title{
Can Cognitive Strategies be Incorporated in a Critical Reading
}

\author{
Course? \\ Nizar Kamal Ibrahim ${ }^{1 *}$ \\ ${ }^{1}$ Languages Department, Faculty of Education, Lebanese University, Beirut, Lebanon \\ *Nizar Kamal Ibrahim, E-mail: pronizar.ki@gmail.com
}

\begin{abstract}
This study examined the effect of training in cognitive reading strategies in the context of critical literacy. Thirty students enrolled in a critical analysis course at a Lebanese university participated in the study. For three months, the participants received instruction based on a critical literacy model during which they were trained in summarizing, paraphrasing, using key words and discourse markers to find details and guessing meaning from context so that they comprehend the texts and read them critically. The Mixed Research Method was used in the study. In the quantitative part, the One-group, Posttest Pretest design was employed. For qualitative data, all the participants filled out a questionnaire. Eleven participants were interviewed, before which they filled out a survey. Also some class interaction was documented. The study also examined how students engaged texts critically, but this data was not presented in this report, which only discusses the results related to the targeted reading strategies. Statistical analysis showed a significant improvement in paraphrasing and summarizing but not in answering detail questions and guessing meaning from context. The qualitative data revealed interesting insights into why students did well in the first two strategies and badly in the last two ones.
\end{abstract}

\section{Keywords}

cognitive reading strategies in a critical analysis course, strategy training in context, beliefs and performance in strategy training, the role of direct instruction in critical reading

\section{Introduction}

Many critical literacy scholars critique the focus of the cognitive approaches to reading on cognitive and meta-cognitive strategies to the neglect of meaningful reading. According to them, this focus ignores the social nature of reading, in which readers interact with texts that are influenced by the author's hidden assumptions and belief systems (Luke \& Dooley, 2011; Wallace, 2003). In response to the reductionist instruction that results from the cognitivists' emphasis on reading strategies, critical literacy scholars stress the critical explorations of texts, de-emphasizing cognitive and meta-cognitive reading strategies in instruction. Such critical explorations engage students in challenging the texts' authority and questioning the views these texts present because the cultural, historical and political 
situatedness of texts reinforce stereotypes and marginalization (Luke \& Dooley, 2011). As Wallace argues, the interest of critical literacy is not in cognitive and meta-cognitive reading strategies, but in the nature of stance taken when reading a certain text as expressed in the reader's critical and meta-critical responses. This raises the question: Can we develop a critical reading model that incorporates reading strategies as means that help students access texts before they engage them critically? In other words, does contextualizing strategy instruction in a critical reading course empower students to understand the text in order to critique it? Would this purposeful instruction be effective? This article discusses the effectiveness of training in summarizing, paraphrasing, using discourse markers and keywords and guessing meaning from context. The training took place in the context of critical reading, but although data about the participants' critical reading were collected, they are not discussed here due to space limitation.

\section{Literature Review}

Critical reading scholars believe that social, ideological, personal, and cultural factors mediate the acts of producing texts and interpreting them. This, according to them, calls for engaging students in critical reading (Luke \& Dooley, 2011; Luke \& Freebody, 1997; Zhang, 2009). Critical reading focuses less on individual responses to texts and more on communally negotiated responses, in which students in the classroom are involved in joint interpretations. This takes place through talk around texts more than through individual responses (Wallace, 2003). Wallace argues that in this approach, there is less interest in problems due, for instance, to the readers' weak skill or strategy than in the ability of the readers to problematize texts. She critiques strategy literature for compiling a list of strategies, sometimes exceeding fifty, which have neither been explored nor taught within a clear theoretical model that explains how they operate in authentic situations. But how are these strategies presented in the literature?

\subsection{Types of Reading Strategies}

What exactly do we refer to when we talk of reading strategies? Are reading strategies the same as the general learning strategies? The term "strategy" refers to the mental processes or behaviors that language learners consciously utilize in second language acquisition, second language use, or second language testing situations (Abbott, 2010). The distinction between reading strategies and more general learning strategies is still being contested. Koda (2005) concludes that no clear cut-lines exist between learning strategies and reading strategies, stating: "Strategic reading is vital in academic pursuits, where reading often is inseparable from learning, necessitating both understanding and retaining complex, often unfamiliar concepts" (p. 205). However, Singhal (2001) distinguishes between the two, explaining that language learning strategies consist of the steps used to learn and acquire a second/foreign language, while reading strategies refer to how readers conceive of a task, how they make sense of what they read, and what they do when they do not understand. Many scholars adopt Singhal's stance, defining reading strategies in different ways. 
Various definitions of reading strategies share the idea that these strategies are deliberate actions initiated and controlled by the reader to solve reading problems and aid comprehension (Abbott, 2010; Chamot et al., 1999; Grabe, 2009; Koda, 2005). Moreover, scholars like Anderson (1991), Chamot and O’Malley (1994), Oxford (1990) and Paris et al. (1991) have offered various schemes to classify strategies. Synthesizing different classification schemes, Koda (2005) and Singhal (2001) present six categories of reading strategies:

1) Cognitive strategies aim to help learners transform or manipulate the language. They include note taking, formal practice with the specific aspects of the target language such as sounds and sentence structure, summarizing, paraphrasing, predicting, analyzing, and using context clues.

2) Memory strategies comprise techniques that help the learner to remember and retrieve information.

They include creating mental images through grouping and associating, semantic mapping, using keywords, employing word associations, and placing new words into a context.

3) Compensation strategies include skills such as inferencing, guessing while reading, or using reference materials such as dictionaries.

4) Meta-cognitive strategies are behaviors undertaken by the learners to plan, arrange, and evaluate their own learning. Such strategies include directed attention and self-evaluation, organization, setting goals and objectives, seeking practice opportunities, and so forth.

5) Affective strategies such as self-encouraging behaviors aim to lower anxiety and encourage learning.

6) Social strategies refer to cooperation with peers, questioning, and asking for correction and feedback.

\subsection{Critical Reading versus the Cognitive Models of Reading}

"Critical reading represents a challenge to the skills-based orientation of many cognitive psychological models which emphasize the building of discrete kinds of abilities" (Wallace, 2003, p. 43). Two of these models that dominate reading instruction, particularly in ESL/EFL contexts, are the Sub-skill Model and the Interactive Model. The Sub-skill Theory presents the most compatible view with how strategies are described in the literature. This theory explains reading as a set of sub-skills that readers must master and integrate. In this view, good readers exhibit automatic and flexible use of the mastered sub-skills while poor readers have not yet learned all the sub-skills and cannot integrate those that they have already learned (Pan, 2009; Roe, Smith, \& Burns, 2009). Actually, no clear distinction exists between sub-skills and strategies. However, Grabe (2009) gives a useful distinction. According to him, when a procedure is consciously evoked to tackle a certain difficulty, it can be termed "strategy". When this strategy is used unconsciously and automatically, it can be termed "skill". This is exactly one important characterization of reading that the Sub-skill Theory maintains. The main problem in the Sub-skill Theory lies in the artificial isolation of the sub-skills, in each of which students receive training separately.

The Interactive Model of Reading also describes readers in terms of their strategic abilities. Its advocates list a number of reading strategies, including text-based or bottom-up strategies and 
meaning-based or top-down ones. However, they posit that strategies in the two categories function simultaneously and interact to construct meaning. Moreover, they argue that background knowledge, formalized as Schema Theory, plays an important role in this interaction. In this view, proficient readers are skilled in both bottom-up and top-down strategies. If readers use one or more strategies overly, it is because there are deficiencies in using other strategies (Alderson \& Urquhart, 1985; Bernhardt, 1990; Carrell, 1988; Goodman, 1988; Grabe, 2009, 1991; Munby, 1978).

Critical literacy scholars and advocates of the Reader-response Theory critique the interactive models in that they isolate reading from its social context and social functions. They believe that the emphasis of the interactive models on the cognitive reading processes has resulted in instruction in bottom up and top-down strategies, "robbing reading of its natural purpose and ignoring its social dimensions" (Leki, 2001, p. 176). The Interactive Models have intended to provide purposes and to lend direction to reading through pre-reading questions, which give students something to read for. But as Leki argues, this understanding of purpose is extremely narrow and limited to language classes. Moreover, the aim is to make students practice reading, in the case of which there can be no internally motivated mechanisms for selecting strategies appropriate for the reader's purposes.

Critical literacy capitalizes on the social nature of reading to engage students in analyzing cultural, social, and political power relationships embedded in texts with the aim of transforming them into more equitable and just ones (Luke \& Dooley, 2011; Wallace, 2003). Through reading socially, economically, and politically coded texts, knowing how codification takes place, and gaining some critical distance from these texts as objects to be talked and written about, critical literacy empowers people with a greater understanding of and control over the circumstances of their daily lives (Freire, 1972; Luke \& Dooley, 2011). In this view, schema is not only a cognitive structure that stores knowledge, but it is socially and culturally formed. This, according to Wallace (2003), makes schemata stereotypical, reinforcing prejudices, unexamined judgments about everyday reality, kinds of behavior, and stock responses to the unfamiliar. The author contends that critical literacy aims to disrupt the functions of schemas so that readers do not conform to schema mandated stock responses. It encourages "diverse interpretations of the same text in a social setting like the classroom. This does not mean that consensus will not emerge over time, but it will be rationally-based, reflected upon and open to critique, not founded on a given, unanalyzed common sense" (Wallace, 2003, p. 23). Thus, critical reading empowers students with a questioning stance not just regarding the texts they read, but also regarding their ideological views as readers. "If asked to verbalize their responses to texts, readers may reveal not just their strategies as readers at the micro level of response to individual utterances, but their stance both critically, conceptually and affectively, influenced by their personal and social histories as readers" (Wallace, 2003, p. 23). In this sense, critical reading is less concerned with specific strategies than with an overall stance or position, an orientation to the reading task. 


\section{Research Problem and Research Questions}

Despite the call for critical literacy in ESL classes, ESL instruction in many contexts gives little attention to critical literacy for a variety of reasons. Most ESL/EFL language textbooks are dominated by strategy drills and exercises and are motivated by practical concerns (Leki, 2001; Wallace, 2003). Due to the inappropriate implementation of the very famous "pre-reading, during reading, post-reading" formula, every reading lesson in these textbooks repeats the same pattern of drills and exercises. This leads to unsystematic reading instruction that does not address a broad range of objectives and does not target critical literacy. My work with Lebanese teachers in in-service training programs for more than ten years confirms that most teachers follow textbooks mechanistically and certainly do not teach critical reading and writing. Zoghi, Mustapha, and Rizan (2011) have documented similar observations in other countries. In response to this formulaic teaching, critical literacy scholars argue for engaging students in critical text analysis, de-emphasizing cognitive and meta-cognitive reading strategies. However, the emphasis on strategies reflects the teachers' genuine concern to help learners become skilled readers as well as pass the different types of exams. Also the interest of critical literacy scholars in engaging students in critical text analysis reveals a valid concern. Are these two concerns exclusive? Can they be targeted as complementary aspects of reading? Hammoud and Macken-Horarik (1999) maintain that skill instruction, language support and critical literacy should be viewed as complementary in an ESL language program. As Wallace (2003) argues, a Critical Literacy teacher teaches facts and prepares students for standardized tests, but he/she adds a critical component, which according to Kanpol (1998), includes analysis, multiple interpretations, and moral reasoning. With this in mind, the following questions are asked: is it beneficial to train students in cognitive strategies to help them access the texts in order to analyze them critically? In other words, do students develop their cognitive reading strategies as a result of skill instruction in a critical literacy course? How do students react to such training?

\section{Methods}

\subsection{Participants and Context}

Thirty female students enrolled in a critical analysis course at a university in Lebanon participated in the study, but nine of them dropped out. The participants' major was teaching English as a Foreign Language in elementary classes, and they came from different Lebanese districts and diverse socio-political backgrounds. They aged between 19 and 23 years, and most of them belonged to low income families. Only a few of them had good control of English. Many of them showed a significant weakness in reading and writing in English.

The critical analysis course is one of five language courses required for the B.A. of teaching English at the university where the study took place. The course aims to develop the students' analytical reading and writing skills. The students read and analyze a number of texts, and they write an analytical paper about a text of their choice. 


\subsection{Research Design}

The Mixed Approach (Qualitative and Quantitative) was utilized in the study. The qualitative part consisted of the following tools:

1) Interviews with eleven participants to explore their explanation of their performance in the posttest particularly and in the course generally;

2) A questionnaire that the interviewees filled out about the usefulness and functions of reading strategies and their utility in independent reading;

3) Another questionnaire was filled out by the whole class to evaluate the effectiveness of the instructional treatment;

The qualitative data was grouped under themes that emerged from the data itself. This data was analyzed thematically.

The quantitative part employed the One-group Pretest Posttest Design (Gay, Mills, \& Airasian, 2009). The pretest assessed the participants' ability to use the cognitive reading strategies targeted in the course and to analyze texts critically. It was also used to divide the participants into less skilled readers and more skilled readers. The participants then received instruction based on a critical reading model. At the end of instruction, they sat for a posttest, which aimed to determine the effectiveness of the treatment. Two tests were used for statistical analysis: T-test and Mann-Whitney test. The T-test aimed to determine the effect of training on the participants regardless of whether they were less skilled or more skilled readers. The Mann-Whitney test aimed to determine whether the less skilled readers or the more skilled readers benefited more from the training.

\subsection{The Treatment}

The instructional treatment has utilized a Critical Reading Model developed by the researcher. The model consists of four non-linear phases: (1) Accessing the Text, (2) Direct Instruction, (3) Problematizing the Text and Responding to It, and (4) Going beyond the Text. In Accessing the Text, students do authentic tasks and pedagogical activities that engage them in constructing meaning. The Direct Instruction phase supports students with the vocabulary, grammar and strategies they need to access the text or to critique it. In Problematizing the Text, students respond to problematic issues embedded in the text or related to it. These responses reveal the students' emotional reactions and ideological views pertaining to the issues that the text presents. In going beyond the text, students take a distance from their initial reactions as well as from the claims that the text makes and read the text from different perspectives. They examine the values that the text promotes and the views it emphasizes as well as those it marginalizes. They also examine the social, economic or political implications of ideas and/or reasons of events and situations discussed in the text.

This model shares with other critical literacy models (Luke \& Dooley, 2011; Wallace, 2003) their emphasis on critical literacy. However, it differs from other models in that it balances between critical reading on one side and skill instruction and language support on the other side. In addition to its emphasis on critical literacy, it aims to help students acquire different reading strategies and the 
language they need for comprehending the texts so that they can be engaged in reading them critically. In order to help students become critical, independent and skilled readers, the model is characterized by a visionary and systematic incorporation of transactional, intellectual and aesthetic authentic reading tasks as well as pedagogical purposes for reading. Thus, the first two phases in the model provide the support students need for comprehending the texts while the other two phases involve students in problematizing texts and in analyzing them critically.

The participants in the study read environmental, political, economic and religious texts. The major objective in the course was to produce critical text analysis characterized by what Wallace calls "intellectual inquiry". The participants practiced critical analysis with several texts and received feedback before they wrote their two critical analysis papers about texts they chose. In order to help them comprehend the texts which they were going to critique, they received direct instruction in the following strategies:

1) Identifying keywords and discourse markers in order to determine the relationships among ideas in a text and to find details.

2) Skimming and scanning for ideas to be used in analysis and debates.

3) Reading texts thoroughly and summarizing them for different purposes.

4) Paraphrasing ideas in a text when the ideas are difficult to understand or when they will be used in certain tasks.

5) Guessing meaning from context when difficult words impede performing the required tasks.

The participants received direct instruction in these strategies to prepare them to use these strategies in carrying out the course activities. In direct instruction, the teacher/researcher explained the steps involved in each strategy, modeled them in class, provided feedback on their use, discussed their importance in real-life situations, and illustrated their versatile use in different contexts.

\section{Results and Discussion}

Has it been effective to train the participants in cognitive reading strategies: summarizing, paraphrasing, using discourse markers and keywords and guessing meaning from context in order to help them access texts that they had to analyze critically? The results of the T-test and the Mann-whitney test show a significant improvement in the general performance of the participants. Table 1 shows the averages related to the overall performance of all the participants as well as of the two groups (the less skilled and the more skilled readers), and it is followed by the relevant statistical analyses.

Table 1. Overall Test Performance

\begin{tabular}{llll}
\hline Groups & Pretest average (out of 100) & Posttest average(out of 100) & Mean difference \\
\hline The whole class & 33 & 45.5 & 12.5 \\
More skilled readers & 41.5 & 58 & 16.5 \\
Less skilled readers & 29 & 39.5 & 10.5 \\
\hline
\end{tabular}


$\mathrm{T}$ critical value $(\mathrm{Df} 20)=2.84$ at $\mathrm{P} 0.05$. The obtained $\mathrm{T}$ value for the whole class performance (4.6) significantly exceeds the critical value at $\mathrm{p}<0.05$, which indicates the significant improvement of the students' performance in the posttest as a whole.

Regarding Mann-Whitney U-test, obtained P is higher than critical P, which means both less skilled readers and more skilled readers generally benefited from instruction.

$\mathrm{U}=35.50, \mathrm{Z}=1.007, \mathrm{P}=0.3139$

Although the participants' performance in the posttest as a whole has shown a significant improvement, the analysis of the items related to each strategy separately reveals that this gain did not occur in all the targeted strategies. The students' performance has improved in paraphrasing, summarizing, and critical text analysis, but not in guessing meaning from context and detail questions that demanded identifying keywords and discourse markers. A detailed discussion of the quantitative and qualitative data related to paraphrasing, summarizing, guessing meaning from context, and detail questions follows.

\subsection{Paraphrasing}

The participants' overall performance in the posttest has demonstrated significant gains in paraphrasing. Table 2 shows the descriptive statistics that illustrate the participants' improvement. It is followed by the results of the statistical tests that indicate a significant difference between the results of the pretest and the posttest

Table 2. Test Results in Paraphrasing

\begin{tabular}{llll}
\hline Groups & Pretest average (total 16) & Posttest average (total 16) & Mean difference \\
\hline The whole class & 5 & 9. & 4 \\
More skilled readers & 6.5 & 11.5 & 5 \\
Less skilled readers & 4. & 8 & 4 \\
\hline
\end{tabular}

The obtained T-test in paraphrasing (4.9) significantly exceeds the critical $\mathrm{T}$ value at $\mathrm{P}=0.05$, which means there was a significant improvement in the posttest. Moreover, the obtained value of the Mann-Whitney $\mathrm{U}$ - test exceeds the critical value $\mathrm{P}=0.05$, which means that less skilled readers and more skilled readers benefited similarly from training in paraphrasing:

$\mathrm{U}=39.00, \mathrm{Z}=0.751, \mathrm{P}=0.4525$

As the statistical analysis indicates, training in paraphrasing in the context of critical reading benefited a large group of participants significantly, but a small group of participants did not benefit from this training. How did both groups view this training? Some participants stated that training made them recognize that paraphrasing is beneficial in preparing for tests, in better understanding difficult ideas and in presenting these ideas in exams in their own ways. Participants 1,2, and 3, who said they had cooperated in studying for university exams, valued paraphrasing as a strategy that made their university work much easier. Participant 1 illustrated this as follows: "We have tried the strategy of 
paraphrasing. It really worked, and now we feel we are freer to write. We aren't afraid of skipping important ideas." Other participants maintained that paraphrasing had had a positive impact on their reading comprehension. For example, Participant 8 viewed paraphrasing as a tool that helps in text understanding. As the data show, contextualized training in paraphrasing made the participants aware of its different uses and enabled some of them to transfer its use to a variety of contexts.

However, four participants, participants 4, 6, 7 and 9, did not paraphrase well in both the pretest and the posttest. In the interview, they expressed a strong negative attitude towards this strategy. For example, Participant 4 stated: “Since I was young, I had problems with paraphrasing. I don't like paraphrasing. And I need more practice in it. I hate it. I need someone to correct for me, to point out for me what's wrong and correct." Participant 7 explained: "Paraphrasing was difficult. They teach us how to paraphrase, but sometimes we need someone who models it in front of us, to tell us exactly how to do it." Although paraphrasing was modeled in class, Participant 7 said that it was not enough.

The comments of Participants 6 and 7 show that their negative educational experiences with paraphrasing caused them to do poorly in the test. However, their inability to understand some expressions also seems to play a role. Participant's 7 response to the paraphrasing question provides evidence to that effect:

\begin{tabular}{ll}
\hline Original Idea & Re-wording of Participant 7 \\
\hline Geoffrey Trew, consultant in reproductive medicine and & If you only do it for insurance for production and future \\
surgery at IVF Hammersmith, undertakes egg freezing & you really need to have good reasons for it or you \\
for cancer and leukemia patients, but draws the line at & would be doing force police. \\
patients who want to pay their way for personal \\
reasons. He thinks that when egg freezing is not the \\
only medical option, it offers a false insurance policy.
\end{tabular}

The Participant's response shows that her inability to guess the meaning of expressions like "false insurance policy" made her paraphrase incorrectly. Participant's 6 answer also reflects the same problem. Her comment during the interview that she has not "thought of it in that way" upon clarifying the meaning of "false insurance policy" confirms this conclusion. Thus, the inability of these two participants to explain certain expressions appears to partly result in incorrect paraphrasing. In addition, low motivation seemed to explain what one of the participants did on the test. Participant 9, who said that paraphrasing is useless, copied the original idea instead of writing it in her own words. In the interview, she said she had done so because she had thought she did not need to paraphrase. However, when the interviewer probed for more explanation of copying the original idea instead of paraphrasing it, the following dialogue took place:

Participant 9: Maybe I found the language difficult. I did not understand it maybe because I expected it 
to be easier.

Interviewer: so when you were asked to paraphrase, you didn't paraphrase, and when the question asked you to analyze, you paraphrased.

Participant 9: Maybe the ideas were easier. That's why I did the easier one for me ... where I understood the ideas I paraphrased in my own language and where I didn't, I just copied.

Certainly, text difficulty did not constitute the only explanation for how Participant 9 answered the paraphrasing and analysis questions. The part to be paraphrased was not more difficult than the part to be analyzed. In any case, she could have paraphrased and analyzed even if her answers could have been wrong. The fact that she paraphrased what she should have analyzed and copied what she should have paraphrased shows that her motivation to do the tasks, and not only text difficulty, played a role in how she answered the question. Low motivation was repeatedly observed in the Participant's responses to other interview questions. Actually, in both the questionnaire and the interview, she explained that paraphrasing was the least useful strategy because it only requires rewriting the same ideas.

Training in paraphrasing in the context of using this strategy for a variety of purposes (presentation, critical analysis, reporting) made many participants recognize the importance of using it in different contexts and helped some of them transfer its use to their academic work. However, as the data show, the educational experiences, low motivation and language difficulties interacted and made this training less effective with a few participants.

\subsection{Summarizing}

Training has led to statistically significant improvement in summarizing. Table 3 presents the descriptive statistics that indicate this improvement. It is followed by the statistical tests that confirm the significant effect of the treatment.

\section{Table 3. Test Results in Summarizing}

\begin{tabular}{llll}
\hline Groups & Pretest average (total 20) & Posttest average (total 20) & Mean difference \\
\hline The whole class & 5.5 & 10 & 4.5 \\
More skilled readers & 8 & 12.5 & 4.5 \\
Less skilled readers & 4.5 & 9 & 4.5 \\
\hline
\end{tabular}

The obtained $\mathrm{T}$ value (4.2) significantly exceeds the critical value at $\mathrm{p}<0.05$, demonstrating the participants' improvement in summarizing at the end of training. Moreover, Mann-Whitney U-test demonstrates that the two groups benefited to a similar extent from training on summarizing. $\mathrm{U}=47.00, \mathrm{Z}=0.149, \mathrm{P}=0.8812$

The $\mathrm{P}$ value of the obtained $\mathrm{U}$ is $>0.05$ which means that there were no significant differences between the two groups.

Training in summarizing in the context of critical reading did not only lead to significantly better 
grades, but it also made many participants see its functions in authentic situations and contributed to a positive attitude towards it. Actually, six interviewees referred to summarizing as the most useful strategy while only two described it as the least useful. Some participants talked about the various functions of summarizing in authentic situations like reports, analysis articles, websites, etc. They stressed that writing summaries for authentic purposes made them enjoy the process and recognize its different uses. Others described a long-term effect of the training, stating that they started using summarizing in their academic work because it helped in reading comprehension. Many participants maintained that the process of summarizing required them to identify keywords, to distinguish between main ideas and details, and to rearrange ideas in their own ways.

Although contextualized training significantly improved the performance of many participants in summarizing and made them recognize the purposes of using it, a few of them did not benefit from this training. They also expressed a negative attitude towards it. Participant 4, who explained that she did not like summarizing because it had been overtaught at school, reflected an incorrect approach to the task in the following excerpt:

While writing the summary, it was getting too long, so I stopped. For that, I didn't cover all ideas. I covered some ideas. Especially if it includes a lot of ideas, we have to concentrate on more than one idea, so we might forget some. So we have to reread in order to know where's the ideas.

As this explanation shows, the participant had difficulty in deciding which ideas to include in a summary of a three page article. She did not acquire the strategies of summarizing relatively long texts although this skill had been practiced with long texts in the training. She referred this to the fact that at school, they did not use to read long texts. Actually, also other participants complained that one source of difficulties in the training was the relatively long texts they had to read, compared to the short texts they used to read at school. This led two participants to "look randomly" at the text in order to determine what to use for the summary, as they said. In other words, they skimmed and scanned it while a summary requires careful reading to distinguish between main ideas and details.

Another participant, Participant 9, missed some main ideas and included many details because of what she thought was important in the text. She explained: "I didn't mention all of the points because you said summarize; maybe that's why I skipped some ideas, and I went into details because I talked about the women specifically. I felt I don't have to mention all of the ideas so I only mentioned the important ones." When asked how she selected the important ideas, she said: "Maybe according to my opinion." Actually, the participant felt that textual details from stories about women who did egg freezing and about women who opposed it were more important to her summary than some main ideas. Later on in the interview, she suggested that text difficulty was another reason for missing some ideas, as the following excerpt shows: "Because I remember my reaction when I read the article, it was vague, and I answered a lot of questions like vocab and explanation. I read it 3 times and I still didn't get the main idea." As the participant's retrospection indicates, the student's understanding of summary, her perception of the important ideas in the text, and text difficulty interacted and resulted in a poor 
summary.

A third participant, Participant 10, also emphasized how more than one factor can lead to weak summaries. She shed light on how text difficulty and lack of interest in Egg Freezing interacted and made her do poorly in the test. She explained: "Ideas are weak and (copied) maybe because I was in a hurry, because I didn't understand. I told you I wasn't interested in the topic.” Thus, Participant 10 established a relationship between not attending to different test-tasks, not comprehending the text, and not being interested in the topic. This relationship was also confirmed when the Participant explained her performance in detail questions as follows:

(The answer is based on global reading) because I did not understand the article. I wasn't attracted to the ideas of egg freezing... I didn't like the topic. It's mainly about when I couldn't understand the general idea of the text, I couldn't answer any question related to the main ideas, but I tried to take highlights, like some general points just to answer the questions since I don't like leaving empty questions.

As this excerpt implies, the difficulties this participant faced in understanding the text and her disinterest in the topic were possible causes for doing poorly in some test tasks.

The comments of participant 10 imply that she could not deal with a text that she does not like. She has not possessed what I call "tolerance of disinterest", an important characteristic of skilled and independent readers. Because we always find ourselves in real-life situations where we have to read and understand texts about topics that we do not like, we have to tolerate disinterest and deal with such texts. The inability of Participant 10 to tolerate disinterest has interacted with the difficulties she faced in understanding the text. This might explain the little benefit this participant gained from the treatment.

A fourth participant, Participant 11, attributed doing poorly in summarizing to yet another combination of factors: text difficulty and working slow in tests. She justified her performance in that "maybe I was in a hurry because I work slow in the test. First, I read the text. I didn't understand. Then, I repeated it, so most of the questions I didn't have time to write them." Thus, this participant's inefficiency in testing conditions interacted with her language proficiency and resulted in a poor summary, as her explanation indicates.

As the data above reveal, a number of factors interacted and resulted in individual differences that accounted for the poor performance of a few participants. Text difficulty was the common factor that interacted with the inability to summarize long texts, the perception of what to be included in a summary, the disinterest in the topic of the text, and inefficiency in testing conditions. However, as statistical analysis and the explanations of the interviewees who benefited from training in summarizing suggest, training in summarizing that aimed to engage students in critical text analysis improved the performance of many students in this strategy and made them aware of its different uses. Summarizing was found to have a positive effect on reading comprehension by Soleimani and Nabizadeh (2012), who also explored the effect of two other strategies: concept maps that the 
participants filled in and concept maps that the participants created. The researchers conducted their study with ninety pre-university students of intermediate language proficiency, divided into three groups. Each group received training in one of the strategies for five sessions, each of which lasted for twenty minutes.

Soleimani and Nabizadeh's study differs from the present one in that the former was conducted in a contrived setting while the training in the present study was carried out in a university course. In addition, in the present study, the interview data show that many participants became aware that summarizing involves them in reconstructing the texts. The data also reflect the participants' awareness that writing a summary requires the use of more than one reading strategy, including identifying keyword, distinguishing between main points and details, and synthesizing ideas. Some of them have recognized that the purposes for a summary determine what to include in it. For instance, some have mentioned that a summary in an analysis article differs from a chapter summary for academic purposes. This implies that training in this strategy in the context of critical reading made the participants able to appropriate their summaries to their own purposes.

\subsection{Guessing Meaning from Context}

There was no gain in grades regarding the strategy of guessing meaning from context. Table 4 shows the mean difference between the pretest and the posttest.

Table 4. Test Results in Guessing

\begin{tabular}{llll}
\hline Groups & Pre-test average (total 20) & Post-test average (total 20) & Mean difference \\
\hline The whole class & 8.5 & 7 & -1.5 \\
More skilled readers & 10.5 & 8 & -2.5 \\
Less skilled readers & 7.5 & 6 & -1.5 \\
\hline
\end{tabular}

The table clarifies that the averages of the more skilled and the less skilled readers in the guessing strategy decreased in the posttest, but how have the interviewees explained this?

Many interviewees attributed their poor performance on the vocabulary question to the length of the exam. Participants 2, 4, 5 and 6 commented that the text they had to read was too long, which made them do poorly on the vocabulary question. Participant 2 emphasized this as follows: We were really stressed and just as I looked at the exam, I said: "Wow. It's too long and how will I finish it!" maybe if you gave us the exam before, we would really have done better; maybe as homework, am sure we would have had better results." Participant 6 also stressed the same point, stating:

I think when we take this home ... and we are relaxed, I think we will do it better, more specified answers and particular things. We missed them during the limited time in the exam. I could not concentrate.

Other interviewees shared the concern of the participants cited above about the length of the test, but 
was the test really long relative to the allotted time? Actually, the researcher estimated that the students were able to answer all the questions in the given time (two hours). Fifty minutes were thought to be enough to answer the three short keyword comprehension questions, to paraphrase the very short paragraph, to guess the meaning of five words from context, and to summarize the text. Thirty five minutes were thought to be enough to answer the two-paragraph-analysis-question, and 15 minutes were given to allow the students to tackle any difficulties they might face. Why did the participants feel that the time was not enough? Time-management seemed to be one of the factors that made many participants work on the guessing question hastily. Many interviewees said they left this question to the end and gave it little time because they thought it was easy and because they spent more time on the analysis question. They explained that they thought the analysis question was more important than the other questions. Actually, even the participants who complained that the test was long did so also. For example, Participant 1 , who talked about time pressure, said: "I left the vocabulary question until the end. First, I took the question on the ethical appeal and I took time on answering. So I couldn't concentrate on the other questions." As this quotation implies, time-management played a role in the participants' wrong guesses. This was due to the participants' perception of what questions were more important.

As the interviews show, test anxiety interacted with time management and affected how some participants answered the vocabulary question. However, test anxiety and time management were not the only factors that caused some participants' poor performance in guessing meaning from context. Actually, a few participants did not do well in paraphrasing because they could not guess the meaning of certain expressions like "false insurance policy". In addition, some interviewees stated that they did not answer the keyword comprehension questions correctly because there were "hard vocabularies." Thus, the failure of some participants to answer keyword comprehension questions, paraphrase, and summarize because the text included some difficult words and expressions indicated that their inability to apply the guessing strategy effectively made them do poorly on guessing meaning from context. Parry (1996) reached similar conclusions in a study that compared the strategies used by twenty Nigerian secondary students while practicing a reading test as preparation for an official exam and strategies used by twenty five Chinese university graduates in their readings in a university course. The researcher used the introspective method with the Nigerian group and the retrospective method with the Chinese group. She found that the Nigerian participants did badly on questions about details and about meaning of words. For example, only two out of eighteen Nigerian participants responded correctly to a question that asked for a definition of the word "hybrid", and four drew on an inexact remembering of the word meaning. The researcher clarified that the remaining twelve students could not remember the meaning of the word and used the surrounding text as well as their knowledge of the word to form their definitions. According to her, this was complicated by the fact that eleven of them did not know one of the keywords in the surrounding text, which made them construct an incorrect text representation. Similarly, the participants in the present study seemed to do poorly on some questions 
partly because they could not guess the meanings of the words that the text contained. Although they, unlike Parry's participants, stressed that testing conditions caused their poor performance, their inability to apply the guessing strategy was evident in their explanation of how they answered different types of questions in the posttest.

Despite their poor performance on the guessing question, most participants in the present study emphasized the importance of guessing meaning from context in fluent and efficient reading. Seven interviewees mentioned that guessing meaning from context had been used by them in their academic work and in their independent reading. Three chose it as the most useful strategy, while only one selected it as the least useful. In the interviews, Participants 1, 2, 3, and 4 explained how guessing meaning from context made their reading easier and faster and led to better comprehension. Participant 1 even mentioned that this strategy made her do tests more effectively. Participant 11 stated that guessing meaning from context makes her understand the meaning of the whole text.

The data show a contradiction between the students' performance in the guessing question and their perception of this strategy. This implies that it is difficult to assess the effectiveness of the guessing strategy through timed tests. Readers resort to this strategy when they deem that the exact meaning of the word is not necessary and that wrong guesses do not affect their purposes for reading. In a test, however, giving the right meaning of the word is crucial, and wrong guesses have negative effects on the grades. Readers in non-testing situations resort to the guessing strategy when they estimate that they have enough clues to do it, while in testing situations, the contexts might contain difficult words or structures that complicate the guessing task and lead to wrong guesses. In other words, guessing in tests defy the purposes of the guessing strategy in independent reading. This might explain the contradictory data in the present study. The positive view of this strategy might result from the participants' ability or willingness to use it in their independent reading, while their poor performance on the test might have come about because of the testing conditions. In independent reading, students choose the words to guess, to ignore, or to look up in the dictionary at their own pace, while tests force them to do it within time limits regardless of their familiarity with the contextual clues and regardless of their estimation of the importance of identifying the exact meaning of the word. However, it might be possible that training in guessing does not help students use this strategy effectively, but it made them appreciate it. Students might have thought that they had mastered the guessing strategy while actually they had not.

\subsection{Identifying Keywords and Discourse Markers}

One of the strategies in which the participants received training was identifying keywords and discourse markers to understand the relationship among ideas and to find details. However, both more skilled readers and less skilled readers did not seem to benefit from this training, as Table 5 shows. 
Table 5. Test Results in Identifying Keywords and Discourse Markers

\begin{tabular}{llll}
\hline Groups & Pretest average (total 14) & Posttest average (total 14) & Mean difference \\
\hline The whole class & 7.5 & 6. & -1.5 \\
More skilled readers & 8.5 & 7.5 & -1 \\
Less skilled readers & 7.5 & 5.5 & -2 \\
\hline
\end{tabular}

The low averages in table 5 indicate that most participants failed to use keywords and discourse markers in answering questions about specific details or about the relationship among certain ideas. This finding is corroborated by Mi-jeong Song's (1998) study which has explored whether or not strategy training enhanced the reading ability of EFL college students, whether or not there was a relationship between the reading proficiency of the students and their gains from training, and whether or not some strategies were influenced more than others by the training. Similar to the present study, Mi-jeong Song's research has been carried out in an ongoing university ESL class. However, unlike the present study, the training in Mi-jeong Song's study has intended to provide students practice in general reading comprehension, following the famous pattern of pre-reading, during reading, post-reading in instruction, while the present study has provided strategy training and has employed a variety of pedagogical and authentic activities that aimed to enable the students to read critically. In addition, the qualitative data in the present study reveal that the poor performance of the participants in detail questions occurred because most of them depended on global reading (the general idea of the text) in answering such questions. One of these questions is:

\begin{tabular}{ll}
\hline Question: & Answer: \\
\hline \multirow{2}{*}{ What particularly makes egg freezing debatable? } & It is the commercial potential for egg freezing that \\
& makes it particularly contentious. \\
\hline
\end{tabular}

The question includes two keywords that are found in the answer: "particularly" and the synonym of "contentious". The students have learned the meaning of "contentious" during guessing meaning from context sessions. Many participants have not given the right answer to the question, but have talked about the views of the opponents and supporters of egg freezing, which are pervasive throughout the article. In other words, the participants have approached the text globally in answering a question about a specific detail, which is indicated by a specific discourse marker. The interviewees have given a number of causes for this.

Some interviewees asserted that they found the general idea of the text relevant to the answer, which made them depend on global reading rather than on looking for particular keywords. For example, Participant 2 explained that she used the different pieces of evidence found in the text to construct her answer. This was why she did not feel she needed to look for specific keywords. Participant 7 
elaborated on this saying: "Maybe I thought that I have to mention the overall point of view of the writer." When asked about how she looked for answers to the keyword questions, Participant 6 said: "I search for the issue, the main things." Participant 5 explained: "Maybe I thought that we must talk about the influence of egg freezing on women and how the writer gave his opinion about (it) or the women that have problems and women that don't have problems. I searched for opinions around this issue." Thus, this group of participants thought that global reading was the right approach to answering the key-word questions. In the following excerpt of the interview, Participant 9 illustrated how her inattention to the discourse marker in one of the questions made her read globally to answer it:

Participant 9: Maybe my concentration was on the question itself. I just put what you want from the question and answer it without giving attention to the keywords. Because I give my attention more to debatable and not particularly... because it may not be one particular thing.

Interviewer: if there is more than one particular thing, then why is "particularly" mentioned in the question?

Participant 9: Because there is one particular thing. I thought in a wrong way. Because as I mentioned before, I didn't look for particularly, I looked for debatable... Why is it debatable? I listed the reasons why is it debatable...

While the participants cited above did not pay attention to keywords in answering detail questions because they thought that their overall understanding of the text was relevant in answering such questions, other participants explained that the difficulty of some keywords and the time needed to search for them and identify their meaning interacted and caused them to depend on global reading in their answers. For example, Participant 1 stated that the keywords indicated in some questions were hard, which caused problems in tracing the answer in the text. Participant 3 explained that: "through global reading, we can be more on the safe side, because maybe we analyzed the word in different meaning or something like that", or as Participant 4 noted: "because we didn't know what the word contentious means.” Thus, some participants' fear to explain some keywords incorrectly made them use an inappropriate approach to answer detail questions. They felt that answering these questions based on their holistic understanding of the text was safer.

Some participants referred approaching the text globally in answering detail question to time pressure. For example, Participant 7 stressed that the pressure of time did not allow her "to reread the text twice, so directly we look at the answer from... the general idea of the text." Participant 1 illustrated how this fear of losing time made her ignore the discourse marker and read holistically in answering the key-word question mentioned before. She said: “In the test, I didn't care if he said particularly or not. All I cared about understanding the question. Maybe we didn't focus on the keywords. We were very stressed up to a level where we understood the global meaning and we didn't go specific in the questions." Participant 3 highlighted the interaction between difficult keywords and time pressure. She stated: "It takes time to search for a keyword in a text, for example to find the word and understand the meaning." Thus, as these retrospections show, many participants resorted to global reading in 
answering detail questions because they did not know the meaning of some keywords, because they were afraid of not finishing on time, or because of both.

\subsection{Holistic versus Disconnected Reading}

Why haven't the participants done well on detail questions while they have done significantly better on summaries, paraphrasing and critical analysis? The data imply that holistic reading used in answering both types of questions made students do better on what Parry (1996) calls higher-order questions than on lower-order ones. Parry has found similar results in her study, in which the Nigerian participants did relatively better on higher-order questions that demanded them to paraphrase, summarize, and synthesize different ideas in the text than on lower-order ones that asked for specific details. The researcher explains that the participants read holistically in answering both types of questions, which worked with the former but did not with the latter. She attributes this to the participants' dependence on top-down strategies. However, the data in the present study suggest that the participants have used a variety of top-down and bottom-up strategies in performing some test tasks. Many participants have emphasized that they used keywords and discourse markers to distinguish between main ideas and details in writing their summaries. They also have pointed out that they supported their critical analysis with relevant details from the text by using keywords. This implies that they used a variety of bottom-up and top-down strategies in constructing their responses to the summary and critical analysis questions. In critical analysis, for instance, they have read holistically to come up with an analysis point and they have skimmed and scanned the text to find supporting details. This means that they altered their mode of reading between looking for details and reading globally in answering higher-order questions like critical analysis and summaries, as a number of participants stated. These explanations reveal that the participants used both top-down and bottom-up strategies in some test-tasks, but why haven't they been successful in answering detail questions, which requires more dependence on bottom-up strategies? Some participants' comments indicate that the difficult keywords in some questions made them feel that global reading was safer. Other responses show that some participants felt that global reading was appropriate. In addition, some data imply that the participants inappropriately used holistic reading in answering lower-order comprehension questions because of the disconnected reading that such questions demand. A group of interviewees have stressed that the problem in such questions is that they ask for bits and pieces of information, the search for which can be complicated by the difficult words that surround this information and by the time needed to identify their locations in the text. Many interviewees have noticed that disconnected reading operative in answering detail questions does not involve them in comprehending the text while summary, paraphrasing, and critical analysis questions engage them in meaning construction. Many interviewees have emphasized that they prefer higher-order, meaning-construction tasks than skimming, scanning, or other comprehension questions because the former challenge them to read for a purpose while the latter require the identification of bits and pieces of information for no purpose. This implies that contextualized training in the use of keywords and discourse markers was more successful with 
higher-order tasks than with lower-order ones. Actually, some interviewees have stressed that they have transferred this strategy to their independent reading, but they have failed in using it in lower-order questions because such questions limit the reader to a small portion of the text and do not help him connect it to other parts.

\section{Conclusion}

Strategy training in a critical reading course distinguishes this study from other strategy research, most of which have examined training in cognitive and meta-cognitive reading strategies in contrived instructional settings. Also, asking the participants to reflect on their performance in the posttest contributes to the originality of the study. In addition, the issue that the study addresses--integrating language and strategy instruction with critical literacy in teaching reading --is a matter of controversy among scholars (Hammoud \& Macken-Horarik, 1999; Wallace, 2003). The researcher adopts the view that both aspects of reading instruction are complementary. In fact, the critical reading model used in the study provides strategy instruction and language support based on what students need to be engaged in critical reading. It seems that this contextualized training helps many students use both top-down and bottom-up strategies in higher-order, meaning-construction reading tasks like summarizing, paraphrasing and critical analysis, but not in answering lower-order detail and guessing meaning from context questions. The results also indicate that systematic instruction in reading strategies that aims to help students carry out authentic transactional and critical reading tasks makes students aware of what strategies to use in authentic contexts. Actually, many participants have maintained that such instruction made them transfer purposeful and appropriate strategy use to their independent reading. These results suggest that second language students should be involved in authentic, transactional and intellectual reading tasks that help them understand texts and examine them critically, and they should be provided with systematic and purposeful strategy instruction and language support in the context of these meaningful tasks. In other words, a systematic reading program addresses a variety of lower-order and higher-order reading skills through balanced instruction that enables students to read for authentic purposes. The results of the study also imply that teachers should be aware of the purposes of teaching strategies like guessing meaning from context and finding details, which should be assessed via authentic tasks in addition to traditional tests. Actually, such strategies are overtaught because of using the same pattern of activities throughout reading courses, which should be avoided by material developers and teachers.

Moreover, the data indicate that text length presented the participants with a challenge. This implies that second language students should practice reading both short and long texts and should be trained to tolerate disinterest while reading. The results also show that a few students did not benefit from the training due to low motivation, weak language, negative school experiences, and misunderstanding of certain tasks that interacted in complex ways. Such students may need a longer duration of training tailored to their needs. 
Finally, although this study has provided interesting insights into how strategy training and language instruction can be incorporated in a critical reading course, it is a small-scale one, carried out with university students in Lebanon. It utilizes the one-group design, which means it lacks a comparison group. Thus, more qualitative and quantitative research is needed to examine the issue of integrating language instruction and strategy training with critical literacy in different second language contexts.

\section{References}

Abbott, M. (2010). An introspective study of Arabic and Mandarin speakers reading comprehension strategies. TESL Canada Journal/Revue TESL Du Canada, 28 (1), 14-40.

Alderson, J. C., \& Urquhart, A. (1985). This Test is Unfair: I'm Not an Economist. In P. Hauptman, R. Leblans, \& M. Bingham Wesche (Eds.), Second language performance testing (pp. 25-43). Ottawa: University of Ottawa Press.

Anderson, N. (1991). Individual differences in strategy use in second language reading and testing. Modern Language Journal, 75, 460-72.

Bell, T. (2001). Extensive reading: Speed and comprehension. The Reading Matrix, 1 (1).

Bernhardt, E. B. (1991). Reading development in a second language: Theoretical, empirical, and classroom perspectives. Norwood, NJ: Ablex.

Byrnes, H. (1998). Reading in the beginning and intermediate college foreign language class. In G. S. Burkart (Ed.), Modules for the professional preparation of teaching assistants in foreign languages. Washington, DC: Center for Applied Linguistics.

Carrell, P. (1988). Some causes of text-boundedness and schema interference in ESL reading. In P. L. Carrell, J. Devine, \& D. E. Eskey (Eds.), Interactive approaches to second language reading (pp. 101-113). Cambridge University Press.

Chamot, A., Barnhardt, S., El-Dinary, P. B., \& Robbins, J. (1999). The learning strategies handbook. New York, NY: Longman.

Chamot, A., \& O’Malley, M. (1994). The CALLA Handbook. Reading, MA: Addison-Wesley.

Freire, P. (1972). Education: Domestication or liberation? Prospects, 2, 173-181.

Goodman, K., (1988). The reading process. In P. L. Carrell, J. Devine, \& D. E. Eskey (Eds.), Interactive approaches to second language reading (pp. 11-21). Cambridge University Press.

Grabe, W. (2009). Reading in a second language: Moving from theory to practice. Cambridge, UK: Cambridge University Press.

Grabe, W. (1991). Current developments in second language reading research. TESOL Quarterly, 25(3), $375-406$.

Hammoud, J. \& Macken-Horarik, M. (1999). Critical Literacy: Challenges and Questions for ESL Classrooms. TESOL Quarterly, 33 (3), 528-544.

Kanpol, B. (1998). Critical pedagogy for beginning teachers: The movement from despair to hope. Retrieved from http://www.lib.umwestern.edu/pub/jcp/issueII-1/kanpol.html 
Koda, K. (2005). Insights into second language reading. New York, NY: Cambridge University Press.

Luke, A., \& Dooley, K. T. (2011). Critical Literacy and second language learning. In E. Hinkel (Eds.), Handbook of research in second language teaching and learning (Vol. 2, pp. 886-902), New York, NY: Routledge.

Munby, W. (1978). Communicative syllabus design. Cambridge: CUP.

O’Malley, J. U., \& Chamot, A. U. (1990). Learning strategies in second language acquisition. Cambridge, UK: Cambridge University Press.

Oxford, R. (1990). Language learning strategies: What every teacher should know. New York, NY: Newbury House Publishers.

Pan, L. (2009). Sub-skills approach and extensive approach to reading in TEFL. Journal of Cambridge Studies, 4(3), 112-120.

Paris, S. G., Wasik, B., \& Turner, J. (1991). The development of strategic readers. In R. Barr et al. (Eds.), Handbook of reading research (Vol 2, pp. 609-640). New York, NY: Longman.

Parry, K. (1996). Culture, Literacy, and L2 Reading. TESOL Quarterly, 30(4), 665-692.

Rosenblatt, \& Louise, M. (2004). The Transactional Theory of reading and writing. In R. B. Ruddell, \& N. J. Unrau (Eds.), Theoretical models and processes of reading (5th ed., pp. 1363-1398). Newark, Del.: International Reading Association.

Roe, B. D., Smith, S. H., \& Burns, P. C. (2009). Teaching reading in today's elementary schools (10th ed.). Boston New York, NY: Houghton Mifflin Harcourt Publishing Company.

Singhal, M. (2001). Reading proficiency, reading strategies, metacognitive awareness and L2 readers. The Reading Matrix, 1(1).

Soleimani, H., \& Nabizadeh, F. (2012). The Effect of Learner Constructed, Fill in the Map Concept Map Technique, and Summarizing Strategy on Iranian Pre-university Students' Reading Comprehension. English Language Teaching, 5(9).

Wallace, C. (2003). Critical reading in language education. New York, NY: Palgrave Macmillan.

Zhang, L. J. (2009). Teaching critical reading to in-service EFL teachers in Singapore. TESOL TEIS Newsletter, 24(1), 1-10.

Zoghi, M., Mustapha, R., Tangku, \& Rizan, N. (2011). Getting to know L2 poor comprehenders. English Language Teaching, 4(1), 98-104. 